\title{
Cyclic Vinyl(aryl)iodonium Salts: Synthesis and Reactivity
}

\author{
Konrad Kepski, Craig R. Rice, and Wesley J. Moran* \\ Department of Chemistry, University of Huddersfield, Queensgate, Huddersfield HD1 3DH, U. K. \\ Supporting Information Placeholder
}

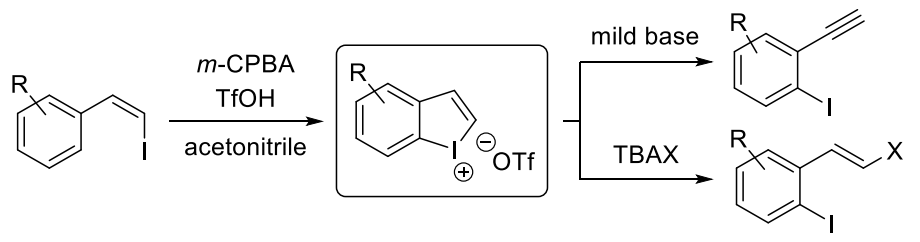

\begin{abstract}
A convenient, highly regioselective synthesis of five-membered cyclic vinyl(aryl)iodonium salts directly from $\beta$-iodostyrenes is presented. An X-ray crystal structure confirms the identity of these heterocycles. These $\lambda^{3}$-iodanes can be converted rapidly into functionalized arylacetylenes by treatment with mild base or undergo $S_{N} V$ reactions with non-basic nucleophiles.
\end{abstract}

Hypervalent iodine compounds continue to attract attention from the synthetic chemistry community because of their useful, often novel, reactivity and their relatively environmentally benign nature. ${ }^{1}$ Iodonium salts are a class of hypervalent iodine compounds that have found applications in synthesis, ${ }^{2}$ as well as in positron emission tomography, ${ }^{3}$ in pharmaceutical applications, ${ }^{4}$ and as radical initiators. ${ }^{5}$ As such, investigations into new iodonium salts and of novel reactivity with iodonium salts are worthwhile endeavors.

Diaryliodonium salts have commanded the majority of attention in this field, ${ }^{6}$ and, in recent years, five--membered cyclic diaryliodonium salts have appeared as reagents and, more recently, as halogen bonding organocatalysts (Figure 1a). ${ }^{7}$ Their transformation into a range of useful heterocycles, ${ }^{8}$ carbocycles,${ }^{9}$ and other molecules is testament to their synthetic utility. ${ }^{10}$ The simplest example, dibenziodolium chloride 1 (aka diphenyleneiodonium chloride or DPI), has found wide application in biological studies as it exhibits potent activity as, for example, a NADPH oxidase inhibitor ${ }^{11}$ and as a hypoglycaemic agent. $^{12}$ In contrast, vinyl(aryl)iodonium salts have received much less attention than diaryliodonium salts, ${ }^{13}$ and the corresponding five-membered cyclic vinyl(aryl)iodonium salts have received almost no attention at all. In 1972, Beringer reported the synthesis of one example in $15 \%$ yield by the low-temperature addition of butyl lithium to diphenylacetylene followed by addition to trans-2-chlorovinyliododichloride (Figure 1b). ${ }^{14}$ Notably, they obtained a single crystal X-ray structure of this intriguing $\lambda^{3}$-iodane. We predicted that a general, facile access to five-membered cyclic vinyl(aryl)iodonium salts could be revealed by the oxidation of $c i s-\beta$-iodostyrenes (Figure $1 \mathrm{c}$ ). It was envisaged that a simple preparation of these $\lambda^{3}$-iodanes would open up their use to scientists in various disciplines. ${ }^{15}$ a) Cyclic diaryliodonium salts - multiple reports

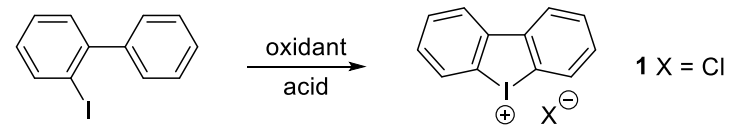

b) Cyclic vinyl(aryl)iodonium salts - one example by Beringer (1972)

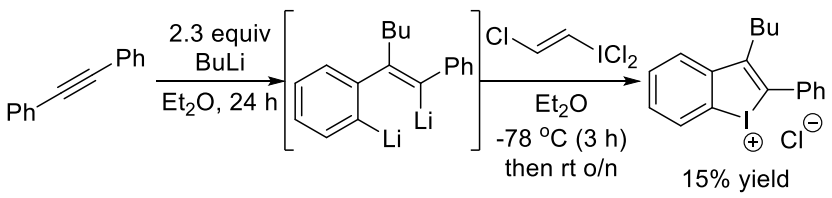

c) This work: a general approach to cyclic vinyl(aryl)iodonium salts $\mathbf{3}$

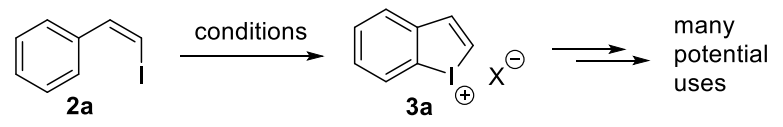

Figure 1. Synthetic approaches to cyclic iodonium salt formation

It was anticipated that cis- $\beta$-iodostyrene $\mathbf{2 a}$ would be converted into the cyclic iodonium salt $\mathbf{3 a}$ upon addition of an oxidant employing similar experimental conditions to those reported for the preparation of other $\lambda^{3}$-iodanes. Iodide $\mathbf{2 a}$ was readily prepared in one-step from benzaldehyde using a Wittig reaction and the conversion of this into 3a was investigated (Table 1). Pleasingly, stirring $2 \mathbf{a}$ in dichloromethane at $0{ }^{\circ} \mathrm{C}$ with $m$-CPBA and triflic acid led to cyclic iodonium salt formation (entry 1); however, the yield was sub-optimal. Increasing the amount of oxidant and acid did not lead to an improvement in yield (entry 2). Lowering the temperature of the reaction vessel to $-10{ }^{\circ} \mathrm{C}$ and $-78{ }^{\circ} \mathrm{C}$ led to a diminishment in yield in each case (entries 3 and 4). Allowing the reaction to occur at room temperature resulted in an increase in yield to $48 \%$ (entry 5), but a further increase to $40{ }^{\circ} \mathrm{C}$ had a detrimental effect (entry 6). Changing solvent to 1,2-dichloroethane or ethyl acetate led to poorer yields (entries 8 and 9), however acetonitrile was found to give superior results (entry 10). Finally, reducing the amount 
of acid gave a slightly diminished yield (entry 11). In addition. replacing trifluoromethanesulfonic acid with trifluoroacetic acid or $p$-toluenesulfonic acid did not lead to any isolable $\lambda^{3}$ iodanes.

Table 1. Optimization studies on the formation of cyclic vinyl(aryl)iodonium salt 3a

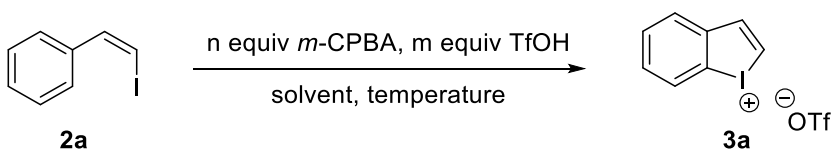

$\begin{array}{llllll}\text { Entry } & \mathrm{n} & \mathrm{m} & \text { Solvent } & \mathrm{T} /{ }^{\circ} \mathrm{C} & \text { Yield/\% } \\ 1 & 1.4 & 2 & \mathrm{CH}_{2} \mathrm{Cl}_{2} & 0 & 27 \\ 2 & 2.1 & 3 & \mathrm{CH}_{2} \mathrm{Cl}_{2} & 0 & 25 \\ 3 & 1.4 & 2 & \mathrm{CH}_{2} \mathrm{Cl}_{2} & -10 & 17 \\ 4 & 1.4 & 2 & \mathrm{CH}_{2} \mathrm{Cl}_{2} & -78 & 4 \\ 5 & 1.4 & 2 & \mathrm{CH}_{2} \mathrm{Cl}_{2} & 20 & 48 \\ 6 & 1.4 & 2 & \mathrm{CH}_{2} \mathrm{Cl}_{2} & 40 & 38 \\ 7 & 1 & 2 & \mathrm{CH}_{2} \mathrm{Cl}_{2} & 20 & 21 \\ 8 & 1 & 3 & 1,2-\mathrm{DCE} & 20 & 31 \\ 9 & 1 & 3 & \mathrm{EtOAc} & 20 & 14 \\ 10 & 1 & 3 & \mathrm{MeCN}_{20} & 53 \\ 11 & 1 & 2 & \mathrm{MeCN} & 20 & 45\end{array}$

With our optimized conditions in hand, we looked at the scope of this reaction with a range of substituted cis- $\beta$-iodostyrenes 2 (Scheme 1). The alkenes obtained from the Wittig reaction contained up to $10 \%$ of the trans-isomers but these isomeric mixtures were subjected directly to the reaction conditions and the iodonium salts obtained were pure. Methyl substituted substrates $\mathbf{2 b}, \mathbf{2 c}$ and $\mathbf{2 d}$ led to clean conversion to the iodonium salts in all cases and, importantly, only one regioisomer of 3c was observed. $m$-Methoxy bearing substrate $\mathbf{2 f}$ was converted into $\mathbf{3 f}$ selectively as one regioisomer. Notably, this is not the same regioisomer obtained with 2c. However, the presence of the ortho- or para-methoxy substituents in $\mathbf{2 e}$ and $\mathbf{2 g}$ led to rapid decomposition of the iodanes at room temperature and no identifiable compounds could be isolated. Piperonal derived iodide $\mathbf{2 h}$ could be converted to iodane $\mathbf{3 h}$ and isolated. The presence of the strongly electron-withdrawing trifluoromethyl group in $\mathbf{2} \mathbf{i}$ led to regioselective formation of $\mathbf{3 i}$. Styrene $\mathbf{2} \mathbf{j}$ with a $\underline{m}$-fluoro group also cyclized to one regioisomer of product, $\mathbf{3 j}$, in the same fashion as $\mathbf{2 f}$. Styrene $\mathbf{2 k}$ with a $m$-chloro substituent also cyclized para to the chlorine in an analogous fashion to $\mathbf{2 f}$. In this case, a very small amount of the alternative regioisomer could be observed in the NMR spectrum (circa 32:1 relative ratio). Cyclization of naphthyl substrate 21 occurred preferentially at $\mathrm{C} 1$ with no trace of the other regioisomer. Introduction of substituents on the alkene were also tolerated and $\lambda^{3}$-iodanes $\mathbf{3 m}, \mathbf{3 n}$ and $\mathbf{3 o}$ were readily prepared.

The yields quoted here are reproducible in our hands, however changes to the standard reaction conditions can lead to augmented or diminished yields which differ from substrate to substrate. For example, increased reaction times lead to lower yields for some substrates but higher yields for others.
Scheme 1. Formation of cyclic vinyl(aryl)iodonium salts 3

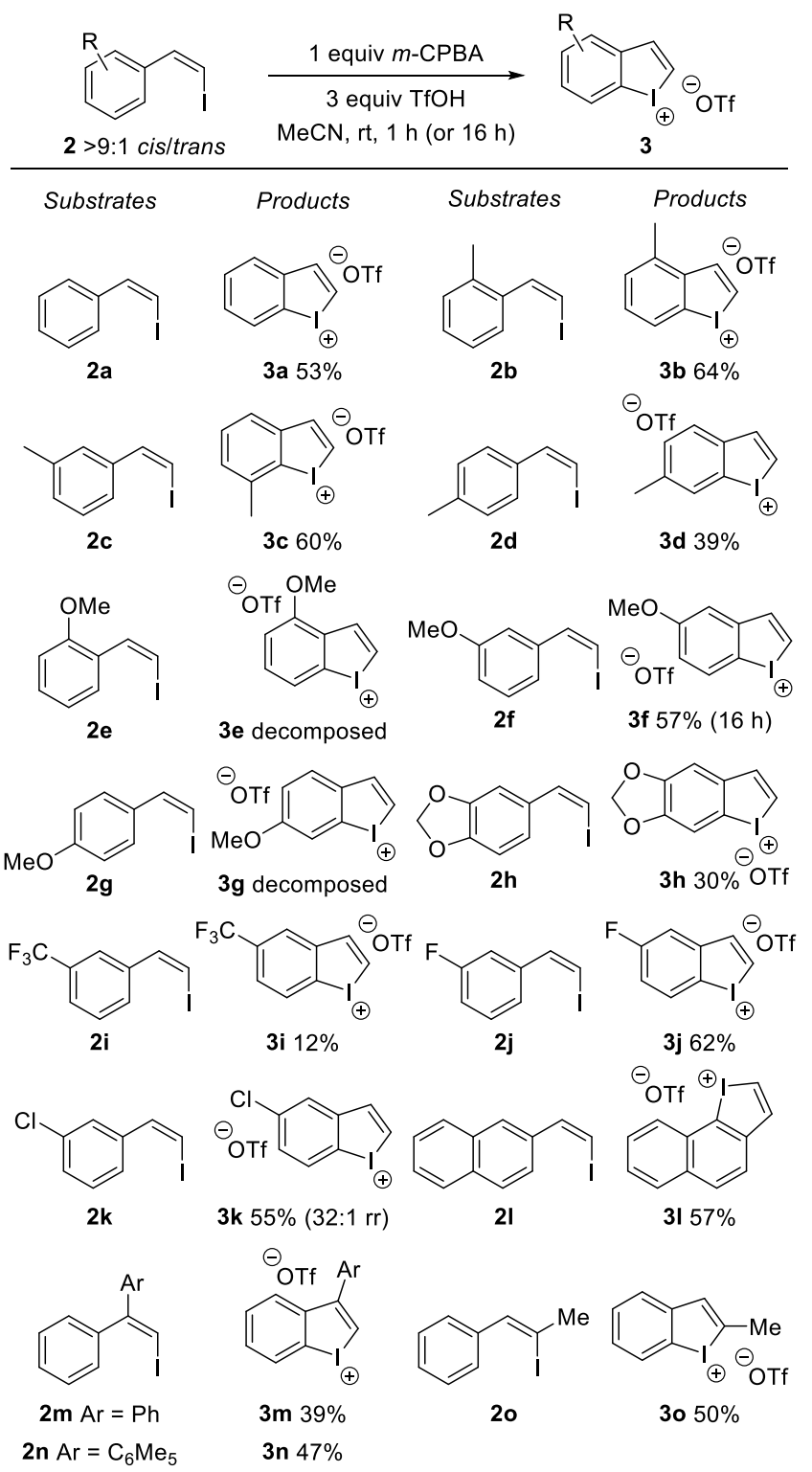

These $\lambda^{3}$-iodanes typically precipitate out of solution as powders or very fine crystals, however, crystals suitable for X-ray diffraction were obtained for $\mathbf{3 a}$ after some experimentation (Figure 2). ${ }^{16}$ In accord with related examples, the crystal structure indicates that the whole molecule is not aromatic and exists as a dimer in the solid state with two loosely bound triflate anions binding together the two iodine(III) centers. ${ }^{14}$ The $\mathrm{C}=\mathrm{C}$ bond is $1.34 \AA$, which is typical for an alkene. The adjacent $\mathrm{C}(6)-\mathrm{C}(7)$ bond is slightly short at $1.45 \AA$, compared to $1.54 \AA$ for a typical single bond, but is longer that the phenyl aromatic bonds which are between 1.38-1.40 . 


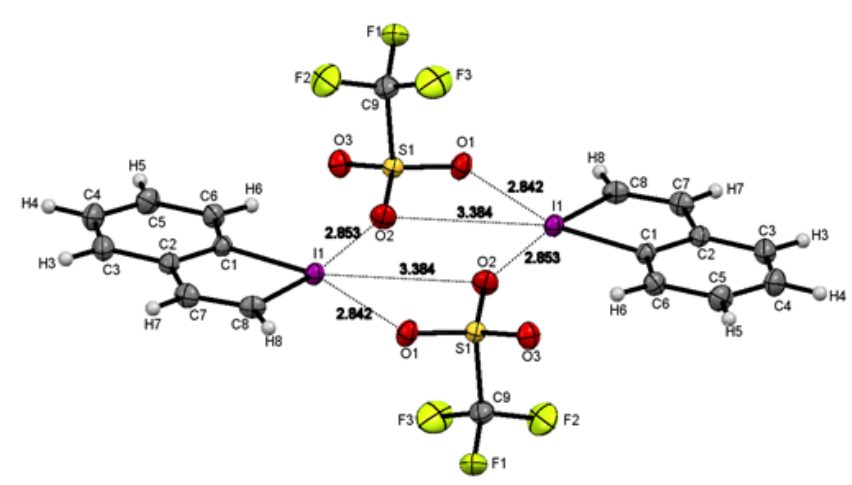

Figure 2. Crystal structure of 3a showing the dimeric nature of the cyclic iodonium salt. Selective distances and angles: $\mathrm{C}(1)-\mathrm{I}(1)=$ $2.085 \AA, \mathrm{C}(8)-\mathrm{I}(1)=2.063 \AA, \mathrm{C}(7)-\mathrm{C}(8)=1.340 \AA, \mathrm{C}(2)-\mathrm{C}(7)=$ $1.451 \AA, \mathrm{C}(1)-\mathrm{I}(1)-\mathrm{C}(8)=82.5^{\circ}, \mathrm{I}(\mathrm{I})-\mathrm{C}(8)-\mathrm{C}(7)-\mathrm{H}(7)=179.93^{\circ}$.

The isolated $\lambda^{3}$-iodanes are stable and can be stored at room temperature under air without any signs of decomposition for several weeks at least. However, treatment with base leads to facile conversion into the alkynes (Scheme 2). In all cases, complete conversion was observed in moments as the poorly soluble iodonium salts were converted into the perfectly soluble products. Triethylamine was found to be an appropriate base for this process whilst pyridine was completely ineffective. This elimination is known with acyclic vinyl(aryl)iodonium salts, ${ }^{17}$ however with these cyclic salts the iodine atom is not lost as it remains attached to the aromatic ring within the products. This two-step process from $\beta$-halostyrenes into arylacetylenes via the iodonium salt is fast and efficient. Literature methods for the conversion of $\beta$-halostyrenes into arylacetylenes typically require treatment with strong bases, such as sodamide or LiHMDS, ${ }^{18}$ although weaker bases such as potassium $t$-butoxide in THF, ${ }^{19} \mathrm{DBU},{ }^{20}$ and tetrabutylammonium fluoride, ${ }^{21}$ have also been shown to be effective. Critically, the halide is lost from the molecule in these examples. Phenylacetylene derivatives are extremely useful compounds and our method allows rapid access into a range of novel examples ready for cross-coupling at two or more positions.

Scheme 2. Conversion of cyclic vinyl(aryl)iodonium salts 3 into alkynes 4

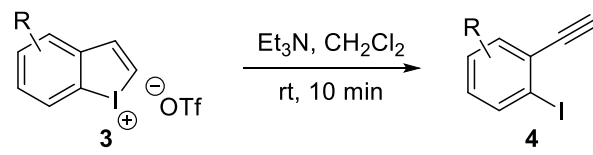

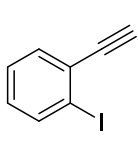

4a $90 \%$

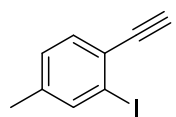

4d $95 \%$

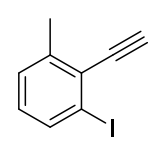

4b $97 \%$

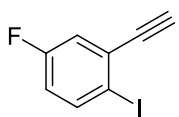

4j $94 \%$

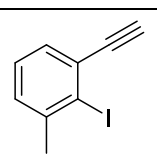

4c $94 \%$

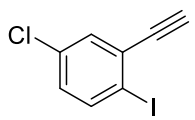

4k $97 \%$
$\lambda^{3}$-Iodanes $\mathbf{3 m}$ and $\mathbf{3 o}$ contain a substituent at positions 2 and 3 respectively which could act as a blocking group preventing conversion to the alkyne. Research with acyclic vinyliodonium salts reported by Ochiai and co-workers suggests that removal of the proton at either $\mathrm{C} 2$ or $\mathrm{C} 3$ is possible but that the former is preferred. ${ }^{17}$ In our hands, $\lambda^{3}$-iodane $\mathbf{3 m}$ with a phenyl substituent at C3 underwent incomplete conversion to alkyne $\mathbf{4 m}$ after one hour upon treatment with base in solvent (Scheme 3). Conversely, $\lambda^{3}$-iodane 3o with a methyl group at $\mathrm{C} 2$ underwent spontaneous conversion to alkyne 40 upon standing in various solvents, including acetone and methanol, without addition of any base being necessary. Unsurprisingly, treatment of $\mathbf{3 o}$ to our standard conditions resulted in very rapid conversion to $4 \mathbf{4 o}$.

Scheme 3. Effect of $\mathrm{C} 2$ and $\mathrm{C3}$ substitution on alkyne formation

(i)

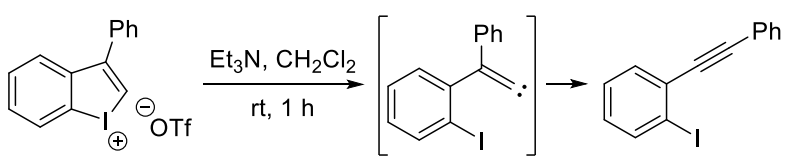

$3 \mathrm{~m}$

$4 \mathrm{~m} 34 \%$

(ii)
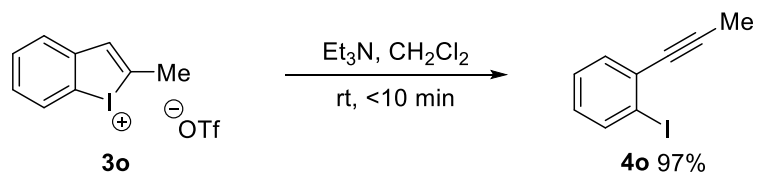

These results suggest that an E2 elimination process is the preferred mechanistic route to the alkyne. Indeed the $\mathrm{I}(\mathrm{I})-\mathrm{C}(8)$ $\mathrm{C}(7)-\mathrm{H}(7)$ dihedral angle is $180^{\circ}$, i.e. it is in perfect alignment for the elimination. Calculations by Apeloig and co-workers have shown that a methyl group significantly stabilizes a vinyl cation, ${ }^{22}$ therefore the methyl in $\mathbf{3 o}$ speeds up the elimination to 40 by stabilization of developing positive charge in the transition state. Conversion of compound $\mathbf{3 m}$ into alkyne $\mathbf{4 m}$ must proceed through $\alpha$-elimination, via formation of a vinylidene intermediate followed by aryl migration, and this is a slower process.

Another useful reactivity of vinyliodonium salts is the vinylation of nucleophiles. ${ }^{23}$ Accordingly, treatment of 3a with weakly basic tetrabutylammonium iodide and bromide led to conversion to the trans-haloalkenes 5 and $\mathbf{6}$ respectively with no evidence of cis-alkene or alkyne formation by NMR analysis of the crude reaction mixtures (Scheme 4). It is likely that this is an example of an $\mathrm{S}_{\mathrm{N}} \mathrm{V}$ process due to the powerful leaving group ability of the iodine moiety. ${ }^{24}$

Scheme 4. Stereoselective ring-opening of cyclic iodane

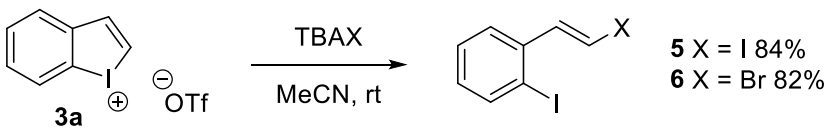

The facile preparation of cyclic vinyl(aryl)iodonium salts is presented. These $\lambda^{3}$-iodanes can be converted into substituted phenylacetylenes upon treatment with base or undergo $S_{N} V$ reactions with non-basic nucleophiles. Future work in our laboratory will concentrate on developing new reactions with these cyclic $\lambda^{3}$-iodanes.

\section{ASSOCIATED CONTENT}

Supporting Information 
The Supporting Information is available free of charge on the ACS Publications website.

Experimental procedures, characterization data and NMR spectra of novel compounds (PDF)

\section{AUTHOR INFORMATION}

\section{Corresponding Author}

*E-mail: w.j.moran@hud.ac.uk

\section{ORCHID}

Wesley J. Moran: 0000-0002-5768-3629

Craig R. Rice: 0000-0002-0630-4860

\section{Notes}

The authors declare no competing financial interest.

\section{Author Contributions}

The manuscript was written through contributions of all authors. / All authors have given approval to the final version of the manuscript.

\section{ACKNOWLEDGMENT}

We thank the University of Huddersfield for funding, Dr Neil McLay (University of Huddersfield) for assistance with NMR spectroscopy and Dr Robert Faulkner (University of Huddersfield) for assistance with recrystallization.

\section{REFERENCES}

(1) Selected reviews: (a) Grelier, G.; Darses, B.; Dauban, P. Beilstein J. Org. Chem. 2018, 14, 1508. (b) Yoshimura, A.; Zhdankin, V. V. Chem. Rev. 2016, 116, 3328. (c) Hypervalent Iodine Chemistry. Modern Developments in Organic Synthesis, (Ed.: Wirth, T.), Topics in Current Chemistry, Vol. 224, Springer, Berlin, 2003.

(2) A general review: Yusubov, M. S.; Maskaev, A. V.; Zhdankin, V. V. ARKIVOC 2011, $i, 370$.

(3) (a) Pike, V. W. J. Label. Compd. Radiopharm. 2017, 1; (b) Altomonte, S.; Telu, S.; Lu, S.; Pike, V. W. J. Org. Chem. 2017, 82, 11925. (c) Yusubov, M. S.; Svitich, D. Y.; Larkina, M. S.; Zhdankin, V. V. ARKIVOC 2013, 364.

(4) For example, see: Das, P.; Tokunaga, E.; Akiyama, H.; Doi, H.; Saito, N.; Shibata, N. Beilstein J. Org. Chem. 2018, 14, 364.

(5) For example, see: Ortyl, J.; Popielarz, R. Polimery 2012, 57, 510.

(6) A review of diaryliodonium salts: Merritt, E. A.; Olofsson, B. Angew. Chem. Int. Ed. 2009, 48, 9052.

(7) Heinen, F.; Engelage, E.; Dreger, A.; Weiss, R.; Huber, S. M. Angew. Chem. Int. Ed. 2018, 57, 3830.

(8) (a) Wang, M.; Fan, Q.; Jiang, X. Org. Lett. 2016, 18, 5756. (b) Wang, M.; Fan, Q.; Jiang, X. Org. Lett. 2018, 20, 216. (c) Yang, S.; Hua, W.; Wu, Y.; Hu, T.; Wang, F.; Zhang, X.; Zhang, F. Chem. Commun. 2018, 54, 3239. (d) Wang, M.; Chen, S.; Jiang, X. Org. Lett. 2017, 19, 4916. (e) Liu, L.; Qiang, J.; Bai, S.; Li, Y.; Li, J. Appl. Organometal. Chem. 2017, 31, e3810. (f) Liu, Z.; Zhu, D.; Luo, B.; Zhang, N.; Liu, Q.; Hu, Y.; Pi, R.; Huang, P.; Wen, S. Org. Lett. 2014, 16, 5600. (g) Riedmüller, S.; Nachtsheim, B. J. Beilstein J. Org. Chem. 2013, 9, 1202.
(9) For example, see: (a) Yang, S.; Wang, F.; Wu, Y.; Hua, W.; Zhang, F. Org. Lett. 2018, 20, 1491. (b) Xie, H.; Yang, S.; Zhang, C.; Ding, M.; Liu, M.; Guo, J.; Zhang, F. J. Org. Chem. 2017, 82, 5250. (c) Liu, L.; Qiang, J.; Bai, S.; Li, Y.; Miao, C.; Li, J. Appl. Organometal. Chem. 2017, 31, e3817. (d) D. Zhu, Y. Wu, B. Wu, B. Luo, A. Ganesan, F.-H. Wu, R. Pi, P. Huang, S. Wen, Org. Lett. 2014, 16, 2350.

(10) For example, see: Xu, S.; Zhao, K.; Gu, Z. Adv. Synth. Cat. 2018, 360, 3877 .

(11) (a) Hong, D.; Bai, Y.-P.; Shi, R.-Z.; Tan, G.-S.; Hu, C.-P.; Zhang, G.-G. Pharmazie 2014, 69, 698. (b) Lien, G.-S.; Wu, M.-S.; Bien, M.-Y.; Chen, C.-H.; Lin, C.-H.; Chen, B.-C. PLoS One 2014, 9 , e104891-e104815. (c) Song, S.-Y.; Jung, E. C.; Bae, C. H.; Choi, Y. S.; Kim, Y.-D. J. Biomed. Sci. 2014, 21, 49. (d) Zhang, G.-Y.; Wu, L.C.; Dai, T.; Chen, S.-Y.; Wang, A.-Y.; Lin, K.; Lin, D.-M.; Yang, J.Q.; Cheng, B.; Zhang, L.; Gao, W.-Y.; Li, Z.-J. Exp. Dermatol. 2014, 23, 639. (e) Moody, T. W.; Osefo, N.; Nuche-Berenguer, B.; Ridnour, L.; Wink, D.; Jensen, R. T. J. Pharmacol. Exp. Ther. 2012, 341, 873.

(12) Holland, P. C.; Clark, M. C.; Bloxham, D. P.; Lardy, H. A. J. Biol. Chem. 1973, 248, 6050.

(13) A review of alkenyliodonium salts: Pirkuliev, N. S.; Brel, V. K.; Zefirov, N. S. Russ. Chem. Rev. 2000, 69, 105.

(14) Beringer, F. M.; Ganis, P.; Avitabile, G.; Jaffe, H. J. Org. Chem. 1972, 37, 879.

(15) Selected recent examples of studies with alkenyliodonium salts: (a) Mészáros, Á.; Székely, A.; Stirling, A.; Novák, Z. Angew. Chem. Int. Ed. 2018, 57, 6643. (b) Liu, C.; Wang, Q. Angew. Chem. Int. Ed. 2018, 57, 4727. (c) Pankajakshan, S.; Ang, W. L.; Sreejith, S.; Stuparu, M. C.; Loh, T.-P. Adv. Synth. Cat. 2016, 358, 3034. (d) Cahard, E.; Bremeyer, N.; Gaunt, M. J. Angew. Chem. Int. Ed. 2013, 52, 9284. (e) Liu, C.; Zhang, W.; Dai, L.-X.; You, S.-L. Org. Lett. 2012, 14, 4525.

(16) Deposition of data at CCDC 1908034.

(17) Ochiai, M.; Takaoka, Y.; Nagao, Y. J. Am. Chem. Soc. 1988, 110,6565 .

(18) (a) Vaughn, T. H.; Vogt, R. R.; Nieuwland, J. A. J. Am. Chem. Soc. 1934, 56, 2120. (b) Wong, L. S.-M.; Sharp, L. A.; Xavier, N. M. C.; Turner, P.; Sherburn, M. S. Org. Lett. 2002, 4, 1955. (c) Giacobbe, S. A.; Di Fabio, R.; Baraldi, D.; Cugola, A.; Donati, D. Synth. Commun. 1999, 29, 3125. (d) Paterson, I.; Steven, A.; Luckhurst, C. A. Org. Biomol. Chem. 2004, 2, 3026.

(19) (a) Matsumoto, M.; Kuroda, K. Tetrahedron Lett. 1980, 21, 4021. (b) Arnold, D. P.; Hartnell, R. D. Tetrahedron 2001, 57, 1335. (c) Okamura, W. H.; Zhu, G.-D.; Hill, D. K.; Thomas, R. J.; Ringe, K.; Borchardt, D. B.; Norman, A. W.; Mueller, L. J. J. Org. Chem. 2002, 67, 1637.

(20) (a) Ratovelomanana, V.; Rollin, Y.; Gébéhenne, C.; Gosmini, C.; Périchon, J. Tetrahedron Lett. 1994, 35, 4777. (b) Quesada, E.; Raw, S. A.; Reid, M.; Roman, E.; Taylor, R. J. K. Tetrahedron 2006, $62,6673$.

(21) (a) Okutani, M.; Mori, Y. Tetrahedron Lett. 2007, 48, 6856. (b) Beshai, M.; Dhudshia, B.; Mills, R.; Thadani, A. N. Tetrahedron Lett. 2008, 49, 6794. (c) Okutani, M.; Mori, Y. J. Org. Chem. 2009, 74, 442.

(22) (a) Dicoordinated Carbocations, (Eds.: Rappoport, Z.; Stang, P. J.), John Wiley and Sons: New York, 1997, Chapter 2. (b) McNeil, A. J.; Hinkle, R. J.; Rouse, E. A.; Thomas, Q. A.; Thomas, D. B. J. Org. Chem. 2001, 66, 5556.

(23) Ochiai, M.; Oshima, K.; Masaki, Y. J. Am. Chem. Soc. 1991, 113,7059

(24) Bernasconi, C. F.; Rappoport, Z. Acc. Chem. Res. 2009, 42, 993. 